\title{
¿POR QUÉ SUCEDEN LAS COSAS ASÍ? Un perfil de Robert K. Merton
}

Morton M. Hunt

Por regla general, una de las recompensas de una profesión es la deferencia que el público otorga a su nombre. Los porteros sonríen a alguien llamado "juez", las mujeres de club se pavonean en torno de un escritor como palomas alrededor de migas de pan viejo, y prácticamente todos lisonjean a un médico como si fuera una especie de taumaturgo. Los sociólogos, que tienen un giro especial para expresar esto -y casi todo lo demás-, dicen que la manera de reaccionar de la gente con relación a una profesión refleja su "imagen popular" y lejos de la indiferencia total, se interesan mucho en la posición relativa de su propia imagen. Robert K. Merton, de la Universidad de Columbia, uno de los miembros más eminentes de la profesión, terminó hace poco un estudio sobre el tema con un párrafo, mezcla de disgusto y optimismo. Escribió: "Las imágenes populares de las ciencias sociales no son ni tan claramente definidas ni tan prestigiosas como las de otros campos profesionales importantes. Cuando los hombres consideran injustificado su humilde estatus, meditan sobre sus orígenes posibles. Entre los científicos sociales surge lentamente un interés por examinar su puesto en la sociedad".

Entretanto, la mayor parte de las demás personas ignora lo que hacen los sociólogos y no les interesa demasiado. Intelectuales como Joseph Wood Krutch y V. S. Pritchett han hablado de la sociología como si se tratara solamente de sacar muestras de opinión pública por medio de encuestas. Con frecuencia las columnas necrológicas dan el titulo de "sociólogo" a los colonizadores fallecidos, y lo más cercano actualmente a la imagen popular de un sociólogo es Vance Packard, quien, de acuerdo con un profesional en tono disgustado, es tan sociólogo como Scopes fue un Darwin".

Merton, un hombre de cincuenta años, alto, de pecho hundido, labios angostos, con anteojos sin marco y conversador tan cuidadoso como el esteretipo de Hollywood de un ministro, porta una sonrisa de abandono que se insinúa burlonamente. Personalmente no se inmuta demasiado con los conceptos equivocados del público, porque su principal "grupo de referencia"-rótulo sociológico de las personas por cuya opinión se juzga la propia- no consta de porteros, mujeres de club y personas por el estilo, sino de sus colegas. Comúnmente se tiene la imagen de un dandi. Sus admiradores lo llaman "un formidable modelo de rol" para los jóvenes de la profesión, y si esto suena áspero y pedante, es preferible a los clisés en inglés llano que le aplican a veces, como "El sociólogo del sociólogo" o "Mister Sociología". Los artículos y los libros de Merton sobre temas tan variados como la estructura burocrática, los lazos entre la religión y la ciencia, y los efectos de la propaganda radial, .se han difundido como diente de león en todo el campo de la sociología y han echado fuertes raíces tanto en los textos como en las notas de pie de página de muchos centenares de escritos técnicos. En 1957 la Sociedad Sociológica Americana (ahora Asociación) reconoció su estatus eligiéndolo presidente. Uno de sus detractores ha tenido que admitir incluso, aunque no de buena gana, que Merton es un "símbolo de prestigio", aclamado por todas las tendencias de la sociología moderna.

\footnotetext{
" Traducido de Morton M. Hunt, "How does it come to be so?" The New Yorker, 36, enero28 de 1961, PP. 39-63. Reprinted by permission; (c) 1961. The New Yorker Magazine, Inc. All rights reserved. Esta edición castellana del texto de Hunt es una versión corregida de una traducción publicada por la Facultad de Sociología de la Universidad Nacional en 1962, en su colección mimeografiada "Lecturas Adicionales". Las múltiples correcciones, que en muchos aspectos terminaron en una nueva traducción española, se deben a Libardo González y Gonzalo Cataño.
} 
Símbolo o no, los vecinos de Merton en Hastings-on-Hudson, en donde habita una casa grande estilo Tudor con altas rejas, tienen poca idea de lo que él hace. La mayoría sabe que es un profesor de sociología de la Universidad de Columbia, que tiene una esposa, tres hijos y quince gatos, y que enciende la luz de su estudio del piso alto todas las mañanas a las cuatro y media. Socialmente lo conocen como a un agradable y festivo compañero que, a pesar de su apariencia poco austera, invariable e infatigablemente despacha el whisky sin mezcla y despliega una sorprendente amplitud de intereses y gran talento para la buena conversación, alterada en algo por el hecho de que está alarmantemente bien informado acerca de todo, desde el béisbol hasta Kant, y listo para hablarle a cualquiera sobre algo o todo lo que le interese. La mayor parte de sus conocidos se inclina a pensar que es una especie de humanista Académico. Un vecino, el escultor Jacques Lipchits, trató de caracterizarlo ante un visitante diciendo: "Merton se interesa en todo lo humano. ¡Recoge mucha Información! Pero no tengo idea en absoluto de lo que hace o lo que extrae de ella. Yo diría que la analiza en alguna forma. Pienso que es un científico".

En cierta manera Lipchits no estaba muy desorientado. Lo que hace Merton en su estudio todas las mañanas después de las cuatro y medía, es evaluar, clasificar y resumir en notas la masa de material extraído de sus propias lecturas, y de encuestas, entrevistas y cómputos hechos bajo su dirección por una docena de estudiantes de posgrado. Escogiendo algún asunto del conjunto de la información del día anterior, lo estudia, se detiene para fumar su pipa y mirar pensativamente al cielo raso, luego se dirige a un archivador de diez gavetas con hileras de índice movible que contienen las miles de cifras y millones de palabras que ha compilado en los últimos veinticinco años, y rebusca en uno de ellos algún documento para compararlo con el papel que tiene ante sí. Después de sacar alguna conclusión de la comparación, hace breves anotaciones en una libreta, examina una cantidad de alusiones oscuras, calcula una desviación normal o un análisis de chi-cuadrado, y teclea sus hallazgos en una máquina de escribir, empleando papel de tres colores diferentes para hacer referencias cruzadas extra especiales. El tema de que se trata puede ser superficial y tedioso (la disponibilidad de niñeras en un pueblo de Connecticut); complicado e interminables (las actitudes variables de los estudiantes de medicina, año tras año, en relación con la preferencia del trabajo clínico opuesto a la investigación), abstruso y filosófico (el concepto de "no pertenencia" en un grupo); pero en casi todos los casos Merton trata primero de descubrir pequeñas -y luego cada vez mayores- semejanzas en su materia prima y desarrollar hipótesis que las sinteticen. Así, su estudio sobre las niñeras lo lleva a una hipótesis sobre la "percepción social", o la manera como la intimidad comunitaria produce confianza y seguridad; su investigación sobre las inclinaciones de los estudiantes de medicina produjeron las hipótesis de que la "adquisición del rol" profesional se realiza gradualmente y su definición de "no pertenencia" se convirtió en parte de una teoría que incluye a los grupos de referencia.

Esta búsqueda de categorías y universales sólo es natural en el caso de una ciencia aún cruda e inmadura, como innegablemente lo es hoy la sociología. Su principal objetivo ahora es formular una cosecha de amplios análisis nuevos del hombre y de la sociedad, logrados por la observación y la experiencia, cristalizados en palabras y frases técnicas. En el peor de los casos estas palabras y frases son simplemente presuntuosas, o a lo mejor son invenciones indispensables para tratar con temas, ideas y técnicas nuevas. $Y$ aunque es muy vaga la idea que la gente común tiene sobre la sociología, algunos aficionados se han vuelto ávidos consumidores de esos productos en su forma más cristalina. Recientemente, los sociólogos han provisto al segmento del público americano denominado "creadores de imágenes" con términos tales como, (aparte de "creadores de imágenes"), "símbolo del estatus", "minoría étnica", "hombre organización", "hombre 
autodirigido", "hombre dirigido desde afuera", "movilidad social" y "retardo cultural". Merton mismo ha añadido un buen número de palabras por el estilo al lenguaje profesional, uno de los cuales, por ejemplo, bajó desde Morningside Heights ${ }^{*}$ hasta la avenida Madison, y desde allí al dominio público. En 1943, cuando seguía a su colega de Columbia, Dr. Paul Lazarsfeld, un matemático y sicólogo vienés convertido en sociólogo, entrevistó veintenas de personas en un pueblo de mediana extensión de Nueva Jersey en un esfuerzo por identificar los medios principales por los cuales se difunden las ideas y las opiniones en una comunidad. Como Lazarsfeld lo había sospechado, se comprobó que los principales propagadores eran ciertas personas persuasivas bien miradas por todos los niveles sociales. Merton se cansó de llamar a estas personas "gente de fuerte influencia interpersonal", y en el folleto que publicó las llamó simplemente "influyentes". Desde entonces la palabra se difundió en los escritos sociológicos de otros autores y recientemente fue empleado por un par de publicistas en el Saturday Evening Post, quienes juzgaron que describía muy bien a los lectores del Post, o que por lo menos presentaba una imagen popular suya muy útil. Cuando apareció en el Times una serie de artículos de mofa al Post en la primavera de 1957, en los que se que preguntaba 'jQuién es el influyente?", Merton los miró atónito, con la mezcla de emociones que siente un hombre que regresa a su hogar paterno, para ver con extrañeza cómo el césped que él solía podar en su adolescencia se ha convertido en una cancha pública.

Es claro que Merton y sus colegas no están empeñados en un semántico acertijo de peluquería con el público. Los sociólogos son herederos de una tradición antigua y seria. Los filósofos griegos, los Padres de la Iglesia, y los diversos filósofos del Renacimiento y del Enciclopedismo, especularon sobre la naturaleza de la sociedad y trataron de ofrecerle prescripciones éticas para su mejoramiento. En el siglo XIX, sin embargo, unos pocos sucesores, percibieron analogía con otros campos del conocimiento, y comenzaron a argüir que el estudio de la sociedad debía considerarse como una rama de la ciencia más bien que de la ética. En 1837 Augusto Comte, el matemático y filósofo francés, inventó la palabra "sociología", y sin arredrarse por la falta de hechos demostrativos detallados, fabricó todo un paquete de dispersas y amplias teorías que se acomodaran a la sociedad -o a él. Pero las ciencias no se afirman tan fácilmente y ninguna universidad del mundo tuvo un departamento de sociología antes de 1892, cuando se abrió uno en la Universidad de Chicago. Harvard ignoró altivamente la nueva ciencia hasta 1930, y en 1939 había menos de mil sociólogos practicantes en los Estados Unidos. Ningún otro país contaba con una cantidad igual. Desde 1939, sin embargo, la profesión ha tenido un notable crecimiento y hoy (1962) la Asociación Americana de Sociología tiene 4.500 miembros regulares y asociados, más dos mil estudiantes próximos a. salir. Pocas profesiones pueden presentar una velocidad de expansión similar.

Por qué la sociología ha crecido tan rápido, es una pregunta complicada, pero obviamente el paso acelerado de los cambios en el mundo y la complejidad evolutiva de la sociedad moderna son factores muy importantes. La sociología mostró por primera vez signos de adquirir cuerno cuando, dejando de lado la gran teorización de Comte, tomó prestados trocitos de técnica a la sicología, la antropología, los estudios de los censos, elaboró retazos propios y empezó a afrontar dolencias sociales especificas, como los tugurios de las ciudades, el divorcio y las pandillas criminales. Posteriormente, sin embargo, estos problemas —aunque lejos de ser completamente entendidos, y de haber sido remediados - han comenzado a parecer menos seductores para muchos sociólogos, que el estudio comprensivo de los fenómenos humanos normales, como la estratificación social, los efectos de la comunicación, la transmisión de la autoridad y la naturaleza de la

*Área donde está situada la Universidad de Columbia (nota del traductor) 
afiliación al grupo. $\mathrm{Y}$ esto ha tocado de repente una cuerda resonante en algunos sectores. Un brujo de tribu agachado cerca al fuego, o aun el empelucado cortesano del período de la Restauración, pudieron haber pensado razonablemente que las cosas seguirían siendo las mismas, y que estaban muy bien preparados por la costumbre y la experiencia para habérselas con los caprichos de sus compañeros y con las crisis de su mundo. Los dirigentes de la sociedad en nuestros volátiles tiempos no tienen una seguridad tan cómoda, y en consecuencia, aun cuando puedan desconfiar de los profesores de sociología, se dirigen a ellos en busca de explicaciones 0 , al menos, de un material que contenga luces. Casi un tercio de los sociólogos en América es empleado directamente en los negocios, el gobierno, los hospitales y las instituciones de beneficencia, y una proporción siempre creciente de la investigación que hacen los dos tercios restantes, que trabajan en instituciones académicas, es sufragada por donaciones externas. El mismo Merton, aunque ha rehusado muchas ofertas para supervisar estudios sociológicos de negocios, industria y gobierno, trabajó durante los últimos 17 años con su amigo Lazarsfeld en la cimentación de la Oficina de Investigación Social Aplicada, en Columbia - un equipo en el cual la palabra dominante es "Aplicada". La oficina fue creada en 1937 por Lazarsfeld como Oficina de Investigación Radial, y su objeto fue estudiar el lugar de la radio en la sociedad americana. Desde entonces ha sufrido una metamorfosis, en parte por los esfuerzos de Merton, para convertirla de obra débil de dos hombres, en una división semiautónoma de la universidad, con setenta empleados y un presupuesto anual de medio millón de dólares. Algunas investigaciones realizadas por la Oficina son sencillamente comerciales (ejemplo, "Efecto comparativo de la propaganda por la radio y la prensa") y otras no están dirigidas primeramente a efectos prácticos (ejemplo, "Los fundamentos lógicos y matemáticos del análisis de la estructura latente"); pero en todo caso sus proyectos son de gran valor para el adiestramiento en investigación de los estudiantes graduados; son muy rápidos debido al uso de máquinas costosas, y son financiados pródigamente por fundaciones, la industria, los sindicatos y el gobierno.

La sociología se ha ido comprometiendo en tantas formas especializadas de actividad, que a duras penas puede hablarse de un "sociólogo típico". En un extremo está el analista de pruebas de opinión que lleva diligentemente el registro de los caprichos del votante y del consumidor; en el otro, está el olímpico teórico de sistemas que imagina oscuras abstracciones sobre valores, estabilidad y cambios, y que espera descubrir la $E=m c^{2}$ de la civilización. En medio están los sicólogos sociales, sumando las características personales de los amantes según el método de matrices matemáticas; los sociólogos de negocios en busca de manchones de Rorschach y tests de respuesta múltiple para obtener débiles luces sobre la estructura de la corporación; los demógrafos que anotan las disminuciones y aumentos de la población de las ciudades y suburbios con la ayuda de los computadores electrónicos; los metodólogos que se tiran mutuamente de los cabellos en los proyectos lógicos y experimentales, y muchos otros. Pero si no existe un sociólogo típico, Merton es por lo menos tan integro que ha hecho algún trabajo en casi todas las especialidades. Unas veces ha timbrado en centenares de casas y ha compilado los resultados y las cifras en resmas de cuadros y gráficos, y otras veces ha vivido con los libros olvidados, polvorientos como un anticuario, mientras trata de relacionar, digamos, las invenciones militares del siglo XVII con el clima social de la época; otras veces ha vivido en las alturas, filosofando sobre la teoría social general conocida como "análisis estructural y funcional". Siempre que habla sobre los objetos y los limites de su profesión, lo que tiene que decir es apto para reflejar su experiencia panorámica. "En la cumbre del pensamiento humano", dijo hace poco en un seminario de Columbia, "algunos sociólogos buscan una teoría unificada —un cuerno generalizado para explicar qué mantiene unidas las sociedades, cómo se acomodan las instituciones en una estructura social, cómo surgen los valores discrepantes y operan sus cambios en una sociedad, etc. Mi amigo y 
colega ocasional Talcott Parsons, de Harvard, ahora está haciendo esto, y pienso que hace progresos útiles. Pero que la mayor parte de las energías sean orientadas en ese sentido sería decididamente prematuro. Einstein no pudo seguir a Kepler tan de cerca, y quizás nosotros no hemos tenido aún un Kepler. Así como la sociología se ahogaría si gastara todo su tiempo en problemas prácticos antes de desarrollar suficientemente una teoría, ocurriría lo mismo si gastara todo el tiempo en teorías abstractas que lo comprendieran todo. Nuestra principal tarea ahora es desarrollar teorías especiales, aplicables a clases limitadas de datos; por ejemplo, teorías de comportamiento divergente, o el paso del poder de generación en generación o las maneras invisibles como se ejerce la influencia personal".

La claridad del lenguaje de Merton es un fenómeno bien recibido en la sociología moderna, aunque algunos de sus colegas de mente más esotérica, juzgan que sus expresiones profesionales no deberían ser tan fácilmente inteligibles. Y cuando Merton accede a las metáforas u otros ropajes literarios - muy raramente usados en sociología, llamados mertonismos por algunos de sus compañeros- su disgusto se convierte en oscura desconfianza. Tachan de herejía frases como "el teórico absolutamente puro corre el riesgo de que, como el decorador moderno, quede con los muebles de su mente desparramados, descubiertos e incómodos".

Peor aún, Merton tiene la inclinación a deslizar pequeños chistes académicos en medio de una discusión seria, como cuando, dirigiéndose a la Sociedad Americana de Sociología hace un par de años, dijo con una característica sonrisa vergonzosa, "ni según las leyes de la lógica, ni bajo las leyes de ningún otro reino, debemos casarnos para siempre con una hipótesis simplemente porque le hayamos dado un abrazo tentativo". Además, muchos de los escritos de Merton están liberalmente aderezados con referencia a la literatura y la historia. En una introducción que escribió para una antología titulada $L a$ sociología de hoy, cita o alude a John Aubrey, Charles Darwin, Herbert Spencer, Séneca, Descartes, Hegel y John Stuart Mili; y otro de sus libros, Persuasión de masas está sembrado de trozos de Thomas Hobbes, Platón, Aristóteles, de Tocqueville, Julian Huxley y Kate Smith.

Todo esto ha confirmado simplemente la sospecha de algunos sociólogos de que Merton, a pesar de su porte grave y académico, es no sólo indecorosamente claro para hablar, sino interiormente frívolo. No ha mucho, un inocente joven colega le refirió esta opinión, y entonces Merton lo atisbó a través de sus anteojos, con mirada fija de lechuza, y suavemente observó: "usted sabe por supuesto lo que dijo San Agustín al respecto: «una cosa no es necesariamente cierta porque esté mal dicha, ni falsa porque esté magníficamente expresada»". "¡Grandioso!", dijo el joven colega, mirándolo con plena admiración.

Por otra parte, un sociólogo de más edad ha observado: "Merton habla menos de lo que aparenta". Ejerce un hechizo sobre los jóvenes, pero sospecho que más tarde ellos se preguntarán a qué se debía su euforia". Para un observador imparcial parecería que, si se introduce un ropaje de gracia literaria en la sociología moderna equivale a hechizar, entonces es un hechizo que vale la pena. Por algún tiempo los humanistas se burlaron de los sociólogos por su tendencia a unir palabras abstractas con la pesada argamasa de cláusulas subordinadas entre paréntesis, creando un muro de prosa impenetrable. Se cita a Talcott Parsons, el amigo de Merton en Harvard, como el más agresivo de todos. En un artículo reciente, por ejemplo, sugiere que una manera de clasificar y diferenciar los sistemas sociales,

se puede llamar quizá con más utilidad eje "instrumental consumatorio". Esto significa que la alternativa de la primacía consumatoria se puede dividir, según la referencia externa-interna, en el caso en el cual los 
intereses consumatorios para el sistema como tal, en relación con la situación externa a él (logro de un fin) constituyen la referencia primaria, y en el caso en el cual los intereses consumatorios de las unidades en sus relaciones de unas con otras (integración) constituyen la referencia primaria. La primacía instrumental, por otra parte, se puede referir, sea a las consideraciones instrumentales para el sistema como un todo relativo a la situación externa, o a los recursos instrumentales significativos de las unidades en sus referencias funcionales internas.

El lector no versado bien puede suponer que esto es un juego de palabras muy sofisticado, y el mismo Merton, aunque fue discípulo de Parsons y admira enormemente su trabajo, admite que algunas veces no puede descubrir fácilmente sobre qué está hablando su antiguo profesor.

En su crítica las cualidades oscurantistas de la mayor parte de la prosa sociológica, Jacques Barzun, el versátil historiador de Columbia, ha escrito en La casa del intelecto, que por emplear repetidamente una abstracción dada, el sociólogo "se afirma gradualmente en la creencia de que la entidad vaga a la cual dio un nombre genérico, existe como objeto". Para esto Merton tiene una respuesta clara. "Hay buena cantidad de jerga sin sentido en nuestros escritos", le admitió a un huésped una noche después de la cena en Hastings. "Pero gran parte de lo que se considera jerga, es el lenguaje técnico que está surgiendo en una ciencia en desarrollo-con medios más precisos y condensados de comunicación que los medios corrientes. El examen de un término consiste en si dice mucho en-poco o poco en mucho". Enderezó su delgada figura en el sofá, echó a un lado de la mesa dos gatos y tomó una copia de Nota para una definición de cultura de T.S. Eliot. "Aquí", dijo, "Escuche esto: 'un hombre puede tener ciertos intereses y simpatías en común con otros hombres de la misma cultura local, así como frente a los de su misma clase en otro lugar, e intereses y simpatía en común con otros de su clase prescindiendo del lugar. Las numerosas divisiones transversales favorecen la paz dentro de una nación al dispersar y confundir las animosidades'. Todo muy bien y claramente expresado; sólo que un sociólogo no más hubiera tenido que escribir 'las series de estatus de corte transversal reducen la intensidad de conflicto social en una sociedad', y hubiera quedado todo dicho, incluso más".

Otra queja sobre los sociólogos modernos es que trabajan mucho y misteriosamente para probar lo que es perfectamente obvio. Merton admite que en ocasiones ha sido culpable de ese pecado. En el verano de 1935, mientras trabajaba en su doctorado en Harvard, gastó varios tediosos meses siguiendo las huellas de los recién graduados del bachillerato, determinando, por medio de intrincadas estadísticas, la relación entre sus calificaciones y el éxito en conseguir empleo. El mundo no se sacudió cuando supo que los estudiantes sobresalientes conseguían trabajo con mayor rapidez que los tornes. Se han publicado centenares de artículos similares cada año en revistas sociológicas que comprueban laboriosamente hipótesis tan evidentes en sí mismas como "Las personas enamoradas se ven mucho más ahora que hace 50 años". (comprobación: cierto). Para los sociólogos, sin embargo, ninguna hipótesis es evidente sin prueba, y esta es la clave de su dilema. La sabiduría de la gente y el conocimiento popular no son necesariamente exactos; efectivamente, para casi todo proverbio hay otro igualmente poderoso que lo contradice. Siendo así, los sociólogos consideran completamente razonable preguntar y examinar toda suposición popular. "No interesa lo que descubramos, estamos en guerra con los Filisteos", dice Merton con un tono algo divertido. "Si encontramos que una creencia ampliamente difundida es verdadera, nos llaman pesados por confirmar algo que sabe casi todo el mundo, y si encontramos que es falsa, nos llaman herejes. Si examinamos una hipótesis que por lo general no se cree y hallamos que es falsa, nos toman por lunáticos por gastar el tiempo y el dinero en una empresa tonta, pero si hallamos que es verdadera, nos llaman charlatanes por decir que algo falso es 
verdadero". En el último verano, dirigiéndose al Congreso Mundial de Sociología en Stresa, Italia, Merton amplió su defensa. "Quizá la polémica más penetrante contra la sociología", dijo, "se origina en el señalamiento de algunos sociólogos de que otros se empeñan diligentemente en el estudio de asuntos triviales, mientras que junto a ellos siguen sin examinarse problemas verdaderamente significativos de la sociedad humana. Este señalamiento supone típicamente que son los objetos particulares bajo estudio los que marcan la importancia o la trivialidad de la investigación. Para algunos de sus contemporáneos, Galileo y sus seguidores estaban obviamente empeñados en un pasatiempo trivial porque observaban las esferas que rodaban por planos inclinados, en lugar de atender a tópicos tan realmente importantes como eran los medios para mejorar la construcción naval".

Felizmente, existen para los sociólogos varias maneras de escapar de este dilema. Una consiste en explicar cómo y cuándo una verdad particular es verdadera, dándole contenido y precisión, elevándola más allá del nivel de la simple perogrullada. Nada puede ser más obvio, por ejemplo, y que un hombre hace amigos sólo entre la gente que suele encontrar y que por lo tanto la casualidad y la geografía juegan un papel importante en las relaciones humanas. Pero Merton, examinando los patrones de amistad en un proyecto de vivienda suburbano, encontró que un factor aparentemente tan trivial como la dirección hacia la cual enfoca la puerta del frente del edificio, es estadísticamente significativ3. Los ocupantes cuyos portones se abren a la calle, probablemente harán amigos en la calle, mientras que aquellos cuyas puertas están a un lado de los edificios, hacen amigos entre los vecinos de la puerta contigua. Sus descubrimientos no tratan de lisonjear a la humanidad, pero como lo anota, la lisonja no es la función del científico.

Otra solución para el dilema de los sociólogos consiste en descubrir algún mecanismo social desconocido en un conjunto de hechos familiares. En Harvard, Merton escogió como tema de su tesis de doctorado la ciencia del siglo XVII, y mientras preparaba el escrito, comenzó a coleccionar información sobre las disputas en que se habían empeñado los científicos sobre la prioridad de los descubrimientos. Por ejemplo, Descartes acusó de plagiario a Hobbes, y Newton armó la gresca con Leibnitz sobre quién había inventado el Cálculo. La reacción del público ante tales contiendas es por lo general "Qué notable coincidencia", o "Pensar que hombres tan grandes sean tan pequeños"; pero Merton penetró en la cuestión, y 21 años después de haber recibido su grado sigue aumentando intermitentemente su archivo sobre el tema, esperando algún rayo de luz que explique por qué hombres tan inteligentes - dedicados todos ellos a la causa de la ciencia y en su mayor parte prudentes y esquivos académicos, que fueron introducidos contra su voluntad por sus amigos en la controversia, siguiendo intereses sinceros,- - fueron tan agrios en el trato entre sí. Hace cuatro años llegó a una conclusión: "Como sabemos por la teoría sociológica de las instituciones", escribió, "la expresión de la indignación moral desinteresada es un signo que anuncia la violación de una norma social". En este caso, prosiguió, la norma social es el derecho de un hombre a la fama, que para el científico es algo más que la simple recompensa de su vanidad; los premios concretos del descubrimiento, a diferencia de los comunes de la tecnología, se pueden derivar solamente de la fama. El reconocimiento de que un científico ha hecho algo primero y dado a conocer después, es por lo tanto el mayor "derecho de propiedad" que puede poseer, y así, concluyó Merton, el asunto de la prioridad se convierte en un asunto social grave que trasciende las vanidades y codicias personales.

Este tipo de análisis —que encierra algún factor insospechado y ofrece una explicación aparente- es lo que más agrada al corazón del sociólogo. Y la inquietud perseverante de Merton por el factor insospechado se refleja a veces involuntariamente en su lenguaje. 
"Ah, seguro, pero ese es solamente el aspecto superficial", dice con frecuencia, y "todo esto aún no pregunta ni responde al problema real. Ahora, si volvemos a plantear la cuestión...". El doctor Kingsley Davis, profesor de sociología y demografía en la Universidad de California, quien conoció a Merton cuando estuvieron juntos en Harvard, dice: "lo que es característico de él y de cualquier buen sociólogo, es su arte de ver el mundo ordinario con ojos extraordinarios. Nos inclinamos a sentir, después de leer un análisis suyo, «No había pensado antes que eso fuera así, pero realmente es así como sucede»".

Se puede argüir que el interés de Merton por la estructura social comienza con su niñez, que transcurrió casi en el fondo de su propia estructura social. Nació en 1910 en un barrio pobre del sur de Filadelfia, en donde las hileras de casas feas y decrépitas albergaron a la primera generación de inmigrantes provenientes de Italia, Irlanda y —los padres de Merton entre ellos- Europa Oriental. Su padre, un hombre pequeño, delgado, de consumado acento eslavo, alternaba entre la carpintería y la conducción de camiones. Pero Merton, el segundo de dos hijos, pasó sus años juveniles en el tipo de ambiente que se condena hoy como incubador de neurosis y delincuencia, no alberga en su mente nada por el estilo; lo recuerda como un lugar amigable, ruidoso e interesante para vivir. La lucha de pandillas era entonces una característica de los barrios bajos como lo sigue siendo ahora, y él se hizo totalmente adepto a una de ellas. "Fui un miembro bueno y leal de mi pandilla", le dijo una vez Merton a Lazarsfeld, quien habiendo crecido en la clase media de Viena, encuentra la infancia de Merton tan curiosa como los dichos populares de Kwakiutle, "pero los asuntos no eran tan peligrosos como lo son hoy. Nuestras fronteras no eran tan rígidas y nuestra asociación no estaba restringida étnicamente. Claro está que yo tomé parte en las luchas de mi pandilla, pero éstas eran más ceremoniosas que mortales. La mayoría de las veces peleábamos a distancia arrojándonos piedras y botellas". Y, como muchos otros niños nacidos aquí de empobrecidos padres inmigrantes, sintió los espasmos de un deseo de saber casi obsesivo; cuando tenía ocho años, se había convertido en visitante regular de una biblioteca pública de la vecindad, en donde leyó extensivamente todo tipo de literatura, mostrando un gusto particular por las biografías. Luego, cuando cumplió los doce años, comenzó a estudiar magia con su vecino de al lado, un exorcista semiprofesional. Los dedos de Merton eran diestros y su lengua bastante persuasiva, hecho que hizo que al poco tiempo estuviera ganando de cinco a diez dólares por exhibición en las funciones sociales del vecindario. De hecho, hubiera podido hacer de la magia su carrera, si no hubiera sido por una exhibición que hizo ante varios centenares de niños en la escuela dominical. Al finalizar, ejecutó el truco de la aguja de Houdini -fingiendo tragar varias agujas y un largo hilo negro, acabándolas de bajar con un vaso de agua, para sacar a continuación el hilo de su boca con las agujas enhebradas. Un par de días después, comenzó a recibir agitados mensajes de las madres que le pedían que volviera a la escuela dominical para que dijera a los niños que todo era un truco, y que los hiciera desistir de comer hilos y agujas. Merton decidió emprender algo menos perturbador y se dedicó a la filosofía. Al ganar una beca en la Universidad de Temple, se matriculó en febrero de 1927 y ocupó los primeros puestos desde el comienzo. James Dunham, que hacía el doble oficio de decano y profesor de filosofía en la universidad, lo consideró un afortunado hallazgo en un campo de estudio en el cual las solicitudes eran cada vez más escasas, pero Merton lo abandonó cuando en su segundo año tomó un curso introductorio de sociología dictado por un joven conferencista llamado George E. Simpson, y en el término de semanas sufrió algo similar a una conversión. "No fue tanto la sustancia de lo que Simpson dijo lo que me transformó", recalca Merton. "Fue más la felicidad de descubrir que es posible examinar objetivamente el comportamiento humano sin emplear preconcepciones morales". Simpson, que era soltero y vivía en la universidad, adoptó a 
Merton, haciéndolo no sólo su asistente de investigación, sino también su principal compañero para beber y charlar.

Hacia 1931, cuando Merton se graduó en Temple y, con la ayuda de una beca, se especializó en Harvard, había adquirido no sólo afición por la sociología, sino también gusto por la música clásica, habilidad para el fox-trot, y para jugar respetablemente un partido de tenis. En el pequeño mundo de la sociología de Harvard, cuyos miembros tendían a ser altivos, y tan cuestionadores como los eruditos del Talmud, los atractivos sociales e intelectuales que presentaban marcaron al recién llegado. La falta de dinero no parecía disminuir su manera de ser — después de todo, había aprendido en su juventud cómo habérselas con muy poco-, y mientras establecía un brillante récord académico bajo la batuta de hombres como Pitirim Sorokin, Talcott Parsons, George Sarton y L. J. Henderson, se las arreglaba mañosamente para sobrevivir con quinientos dólares anuales, hazaña que logró en parte resistiendo largos períodos con sandwiches y leche y fabricando su propio whisky. Su comportamiento agradable ganó también la admiración más allá de los predios de la universidad. "Bob tenía una conducta que era desordenadamente atractiva para las mujeres intelectuales", dice un antiguo compañero de estudios, con un pálido tono de envidia. "Dudo si hubo una muchacha inteligente que al encontrarlo no sucumbiera". La muchacha que le fue especialmente atractiva era una hermosa trabajadora social de pelo rojizo llamada Suzanne Carhart, que había estudiado en Temple con él, y en 1934, cuando Harvard lo nombró profesor, se casó con ella.

A pesar de su sociabilidad en Harvard, Merton fue, como lo ha sido siempre, un trabajador incansable, que vela muchas horas y duerme pocas. Dedicó una de las vacaciones universitarias a visitar todos los barrios de desocupados y las enramadas de los vagabundos de Boston, entrevistando a sus moradores para averiguar quiénes eran, quiénes hablan sido y de dónde venían. Gastó cuatro o cinco meses entre los muros del sótano de la Biblioteca Widener de Harvard, clasificando docenas de miles de patentes aparecidas en los Estados Unidos entre 1860 y 1930, con el fin de contabilizar las fluctuaciones en la tasa de invención de cada industria, para relacionarla a continuación con las condiciones sociales cambiantes. Y para su disertación doctoral leyó con tesón 6.034 biografías en las pequeñas letras del Diccionario de Biografía Nacional justamente como un principiante-. A instancias de sus profesores, Merton remitió ensayos sobre estos tres estudios, como también sobre otros trabajos, a una variedad de revistas científicas, incluyendo el Quaterly Journal of Economics, el American Journat of Sociology, la American Sociological Review, Isis y Osiris, y, cosa extraordinaria, ninguno fue rechazado. Evidentemente, el joven estaba en su elemento.

Hasta cierto punto, esos artículos fueron hazañas juveniles, pero el siguiente esfuerzo de Merton —en 1936, cuando estaba todavía en la mitad de sus veintes - fue una teoría de visión y utilidad tan sorprendentes que, cuando corrieron noticias sobre ella, quedó consagrado de una vez por todas como una figura de primer plano en la sociología. Cuando era estudiante de posgrado, había leído los escritos del sociólogo francés Emile Durkheim, uno de los padres fundadores de la nueva ciencia, quien, después de haber compilado y estudiado las estadísticas sobre las tasas de suicidio en muchos países, expresó su creencia de que diferían de acuerdo con algo llamado anomia; esto es, una ruptura de los estándares sociales que conducen a la falta de cohesión y solidaridad en la sociedad. Merton se asignó a si mismo la tarea de descubrir qué produce la anomia, y finalmente concluyó que es más severa en isis sociedades en las cuales la gente no tiene acceso a los medios adecuados para llevar a cabo sus fines culturales. Si, por ejemplo, una sociedad empuja con fuerza a sus miembros a acumular riqueza (o a alcanzar poder o a santificarse), y ofrece medios inadecuados e inaceptables para realizarlo, la tensión 
resultante hará que muchas personas violen las normas, creando así la anomía. En este punto, Merton juzgó que habla dado quizá con una explicación sociológica para toda clase de comportamiento que quebranta las reglas, y emprendió la tarea de formularla creando combinaciones teóricas de actitudes humanas hacia los fines y los medios, variando cada vez un factor hasta obtener lo que pensó que era una serie completa de cinco categorías. En la primera categoría (Conformidad), colocó a las personas que estaban satisfechas tanto con los fines de su sociedad como con los medios admitidos para alcanzarlos; en la segunda (Innovación), las que tienen simpatía por los fines pero encuentran los medios tan limitados que buscan unos nuevos (el artista de vanguardia, el comerciante perspicaz, el científico radical, el delincuente); en la tercera (Ritualismo), los que pierden de vista los fines pero se apegan ciegamente a los medios como fines en sí mismos (el autómata de la organización, el religioso compulsivo, el pequeño funcionario); en la cuarta (Retraimiento), las que simplemente abandonan tanto el fin como los medios (el vago, el bohemio); y finalmente, en la quinta (Rebeldía), las que tratan vigorosamente de introducir un nuevo patrón tanto de fines como de medios (el verdadero rebelde, el restaurador de la sociedad). Reduciendo esta teoría a una forma breve de registro sociológico, Merton hizo el siguiente cuadro:

Tipología de los medios de adaptación individual

\begin{tabular}{|l|c|c|}
\hline \multicolumn{1}{|c|}{ Modos de adaptación } & Metas culturales & Medios institucionales \\
\hline I Conformidad & + & + \\
\hline II Innovación & + & - \\
\hline III Ritualismo & - & + \\
\hline IV Retraimiento & - & - \\
\hline V Rebelión & & \\
\hline
\end{tabular}

Aunque a primera vista el cuadro pueda parecer frío y poco atractivo, fue para Merton y muchos otros sociólogos un bello panorama, ya que colocaba en una taxonomía fácilmente comprensible, a personalidades tan diferentes como los cubistas y los alcohólicos, los lobos solitarios de la invención y los mártires religiosos, los ejecutivos y los mendigos, los comunistas que portan carteles y los de la Sociedad de Cincinnati. Aunque todo lo que había aprendido Merton sobre el comportamiento aberrante en sus días de pandilla parecía quedar en su lugar, a su edad todavía se sentía poco seguro para publicar un concepto tan comprensivo, que no lo hizo sino dos años después. Lo bosavejó entonces en un breve ensayo que apareció en la American Sociological Review en 1938. Los sociólogos reaccionaron en todas partes con lo que llaman "resonancia" alabándola, atacándola, extendiéndose sobre ella o incorporándola totalmente a sus propios estudios-, y pronto casi todo nuevo trabajo sobre cualquier aspecto del comportamiento desviado se adhería a Merton o criticaba su descubrimiento y manifestaba que podía ofrecer una mejora. "Para ser franco", dice una de estas críticas, "encontré esta tipología demasiado nítida y demasiado cómoda para anunciar la verdad. Pero actualmente no hay ninguna otra teoría generalizada sobre el comportamiento desviado. La tarea que ha hecho es tan pulida y estimulante que hasta que aparezca algo mejor, todos tendremos que emplearla".

Con la publicación de este trabajo, Merton quedó firmemente consagrado como uno de los principales teóricos jóvenes en su campo. Dos años más tarde, avanzó de un salto de su calidad de instructor a la de profesor en Tulane, donde llegó a ser director del departamento de sociología. Su desempeño allí fue sin embargo corto, porque en 1941 aceptó una invitación para unirse a la Universidad de Columbia como profesor asistente en uno de los departamentos más activos de sociología del país, en donde iría a trabajar 
en compañía de hombres como Robert Lynd, el explorador de Middletown, y el erudito Robert Maclver. Sólo algún tiempo después de su llegada a Morningside- Heights supo Merton que se habían solicitado sus servicios tanto por su valor simbólico como por su habilidad. La lucha más encarnizada en la sociología moderna —un campo en el cual hay más disensión sectaria que en siquiatría - está entre los matemáticamente orientados, los empíricos de encuestas de opinión, y los pontificantes teóricos creadores de conceptos. El departamento de sociología de Columbia se dividió tan con tal hondura en estas dos facciones, que por varios años resultó imposible contratar un nuevo profesor, simplemente porque los bandos no se ponían de acuerdo con ninguno. Finalmente se hizo un compromiso: cada bando haría una elección. Los empíricos escogieron a Lazarsfeld, que había creado ya su Oficina de Investigación Radial, y los teóricos escogieron a Merton, en ese momento un excelente espécimen de artífice de conceptos.

Por un tiempo los dos recién llegados tuvieron poco contacto entre si. Hacia noviembre de 1941, Lazarsfeld juzgó que siendo de más edad, debía hacer un acto de cortesía y reconocer la existencia de su contrincante. Invitó a los Merton a cenar, pero la tarde del compromiso recibió una llamada urgente de la Oficina de Hechos y Cifras (la predecesora de O.W.I.), que le pedía dirigir un test de reacción de audiencia esa misma noche en un nuevo programa de radio que había sido ideado por la agencia, como parte del esfuerzo de moralización de preguerra. Cuando los Merton llegaron, Lazarsfeld les salió al encuentro en la puerta de su apartamento y dijo: "Muy bien, muy bien que ya estén aquí. Pero no se quite su abrigo, querido Merton. Le tengo una sorpresa sociológica. Tendremos que dejar que las señoras coman solas y volver tan pronto como podamos". Luego salió con Merton a un estudio de radio, donde una veintena de personas estaban escuchando una transmisión grabada de "Esto es la guerra

oprimiendo botones de "gusto" o "disgusto" conectados a una máquina computadora. Todo esto le parecío aburrido a Merton, quien pensaba con tristeza, en el gulasch y el palatschinken que se estaba perdiendo. Pero después del programa, cuando un asistente de Lazarsfeld cuestionó a la audiencia por las razones que habían dado de su gusto o de su disgusto, Merton se irguió; detectó los defectos teóricos de la forma como estaban haciendo las preguntas. Comenzó a pasarle a Lazarsfeld notas garrapateadas con frases tan cabalísticas como "fluctuación de las curvas poligráficas" y "especificación inadecuada del estimulo real". Lazarsfeld sonrió a su huésped hambriento y garabateó respuestas divertidas. Cuando entró en el estudio la segunda tanda de escuchas, Lazarsfeld le preguntó a Merton si quería hacer el interrogatorio después del programa. Merton lo hizo y su descuidado anfitrión dijo después: "iTrabajo maravilloso! Tenemos que discutirlo. Telefoneemos a las señoras y digámosles que todavía estamos ocupados". Hicieron esto, y de forma poco caballerosa bajaron al Bar del Oso Ruso, donde comieron caviar, bebieron champaña y hablaron sobre sociología hasta muy pasada la medianoche.

Desde entonces Merton y Lazarsfeld han sido colaboradores incansables en la Oficina de Investigación Social Aplicada, y unos amigos muy estrechos. (Característicamente, han sacado una conclusión científica de su amistad en un estudio conjunto publicado bajo el titulo de "La amistad como proceso social").

Con intervalos, durante esta colaboración ha sido coautor de dos libros publicados con la esposa de su amigo, quien en un volumen reciente fue equivocadamente titulado (por otras manos) como "Kendall Patrice L., revisado por Lazarsfeld, Paul y Merton, Robert K.". Se debe en gran parte a su colaboración con Lazarsfeld el que ahora se considere a Merton, no como un teórico típico, sino como un sociólogo multifacético que ve algo bueno en cada una de las fracciones opuestas de la ciencia, siendo al final un campeón de su unidad. La opinión de Merton sobre si mismo, sin embargo, no está pintada con 
alegres colores. A pesar de la impresión externa de brillantez sin esfuerzo que crea, alterna entre la tranquila satisfacción con sus propios esfuerzos y la desesperación con sus defectos; sólo su familia y sus amigos íntimos pueden decir cuáles aspectos se deben a la fama de su aureola. A medida que pasa el tiempo, se ha convertido en un perfeccionista cada vez mayor de su trabajo, inquietándose interminablemente por encontrar la frase correcta, la construcción teórica exacta, el trozo de evidencia empírica apropiado y justo. En consecuencia, ahora gasta nueve o diez años en terminar un proyecto importante y entregarlo a la imprenta - comportamiento extraordinario en un campo en el cual la mayoría de los escritores abruma a los editores de revistas científicas con informes casi semanales sobre cualquier pequeño estudio terminado, cualquier estudio grande medio terminado, y todo estudio grande o pequeño que apenas comienzan.

Todo el contenido de un anaquel en el estudio de Merton, de pastas impecables de cuero carmelita, son los escritos a máquina de libros e investigaciones terminadas con las cuales se podría hacer una respetable bibliografía — sólo si se le pudiera persuadir de que entregara aquellos trabajos a la luz pública. Cierta vez que un conocido lo acusó con gentileza de permitir que el perfeccionismo restringiera indebidamente sus publicaciones, replicó con desacostumbrada aspereza: "por el contrario, he publicado demasiado. Así como pienso que muchos hombres han publicado más que muchos".

A pesar del perfeccionismo, en el último cuarto del siglo Merton ha escrito, editado y colaborado con noventa artículos y libros publicados. Desde 1954 su principal proyecto ha sido la investigación sobre los estudiantes de medicina —un intento por determinar cómo adquieren gradualmente los valores, las actitudes y el equipo emocional de médicos. El proyecto es subvencionado por la Fundación Commenwealth y el trabajo de mayor peso se lleva a cabo en el Centro Médico de Cornell, en la Western Reserve y en la Universidad de Pensilvania, por media docena de jóvenes asociados a Merton. A estas alturas han aparecido sólo un libro y una docena de artículos breves; el resto -centenares de hojas escritas a máquina y de notas - se está añejando en la botella. Otro jamón mertoniano que está en espera de su proceso de curación, incluye un libro sobre sociología de la ciencia, un libro sobre los usos prácticos de la sociología y un buen número de ensayos, artículos y capítulos sobre un balance acerca de la teoría estructuralfuncional. Sus amigos esperan que pronto se dedicará a la magnus opus que esperan que él será capaz de producir —una obra integradora que unirá las partes dispersas de la teoría en una sólida textura. En los días buenos Merton juzga que algunos de sus manuscritos no publicados son el comienzo de tal trabajo; en los días malos se siente triste y piensa que nadie podrá escribir nada por el estilo antes de cincuenta años.

Se puede decir que Merton, empleando los términos de su oficio, es un formidable modelo de rol, cuya imagen entre sus colegas es espléndida, cuya auto imagen es profundamente ambivalente y cuya imagen pública es nula. Se puede agregar que es una personalidad desviante, porque escribe demasiado bien para un sociólogo y se levanta demasiado temprano para un burgués, y también porque vive por elección propia en un barrio racialmente integrado. Como la mayor parte de los sociólogos, Merton sostiene que su actitud hacia los grupos minoritarios deriva menos de sus sentimientos personales que de la evidencia sociológica. En todo caso, cuando los Merton llegaron a Nueva York procedentes de Nueva Orleáns hace unos veinte años, tomaron en arriendo una casa en Hastings y comenzaron a ver posibilidades de comprar una. La casa que finalmente escogieron como la más adecuada para sus necesidades, gustos y bolsillo, se encontraba en un sector llamado Pinecrest, que conocieron como la casi única comunidad racialmente integrada, estable y de clase media en Westcherter. Sin embargo, Merton 
niega que haya tenido que ver algo con su decisión: "A Sue y a mí simplemente nos gustó la casa y el sector", dice. "El hecho de que vivieran ahí negros era accidental —así como lo hicieron algunas personas de origen francés y una pareja de descendientes del Mayflower y otros más. Un liberal de salón diría que todos ellos son seres humanos, o algo parecido. Esto es de buen sentido, pero absurdo. Realmente, ellos son diferentes cultural y socialmente, lo cual me parece interesante. Sin embargo, debo admitir que no consideré esto cuando nos trasladamos aquí. Solamente nos gustaba el lugar". A los Merton les ha gustado desde entonces el sitio, y cuando hace algunos años necesitaron más espacio, simplemente se mudaron 180 metros más abajo. Pinecrest es todavía racialmente integrada y estable, pero el solo liberalismo no ha sido suficiente para mantenerlo así; se han requerido buen número de asambleas comunitarias y de argumentos para evitar que los blancos sucumban a las periódicas olas de resentimiento o pánico, que destruyan la balanza de ocho familias negras frente a cuarenta blancas. En estos esfuerzos Merton ha desempeñado un papel activo, hablando a sus vecinos sobre el asunto en una forma tranquilizadoramente científica. En consecuencia, ha hecho mucho en favor de la imagen local y popular de un sociólogo. Pero todavía tiene problemas con los extraños. En una fiesta, hace algún tiempo, alguien lo presentó como un sociólogo prominente a un congresista, y éste preguntó si Merton accedía a que se le hiciera una pregunta quizás impertinente. Merton lo animó a proseguir. "Bien" dijo el congresista, "considerando entonces la situación actual del mundo, todo lo que se dice acerca de series de estatus, creadores de imágenes, movilidad social, retardo cultural, y cosas similares, francamente me suenan como sin objeto. ¿Por qué ustedes los sociólogos no se ponen a trabajar y contribuyen a algo útil?.

Merton miró pensativamente por un momento y luego, con tono suave y convincente, dijo: "Cuando alguien pregunta para qué es buena la investigación científica, pierde totalmente el punto de partida de la actitud científica, que más bien se pregunta ¿por que suceden las cosas así?"'. Y la respuesta precede a las aplicaciones prácticas. No es por culpa del sociólogo por lo que la sociedad necesite hoy de su ayuda, cuando su ciencia no ha madurado aún. Supongamos que hace tres siglos se le hubiera exigido a Harvey que se limitara al problema de la trombosis coronaria, justamente cuando él estaba tratando de establecer el hecho de la circulación de la sangre. Si la sociología en su estado actual tuviera que aplicarse a los problemas prácticos, nunca se convertiría en la ciencia que usted quiere que sea —una ciencia cuyos beneficios serán tan maravillosos como insospechados".

"Muy bien dicho", dijo el congresista, "pero todavía no entiendo qué están tratando de hacer sus compañeros".

"Esa maldita imagen popular", murmuró Merton dentro del vaso de whiskey que había levantado.

¿QQué dijo usted?, preguntó el congresista”.

"Oh, nada", respondió Merton.

\footnotetext{
${ }^{*}$ Diminutivo de Suzanne (nota del trad.)
} 